\title{
SIDE EFFECTS ASSOCIATED WITH DRUGS USED IN TREATMENT OF MULTI DRUG RESISTANT TUBERCULOSIS AND TREATMENT RELATED FACTORS OF MULTI DRUG RESISTANT TUBERCULOSIS PATIENTS IN KATHMANDU VALLEY
}

\author{
Bhatt CP1 ${ }^{1}, \mathrm{KC} \mathrm{B}^{2}$ \\ ${ }^{1}$ Kathmandu Medical College Public Limited, Sinamangal, Kathmandu, Nepal \\ ${ }^{2}$ Nobel College, Kathmandu, Nepal
}

\begin{abstract}
Introduction: Treatment of multi drug resistant Mycobacterium tuberculosis (MDR-TB) with second line drugs is associated with adverse drug reactions and toxicity. Aim of this study were to determine side effects associated with drugs used in treatment of multi drug resistant tuberculosis and treatment related factors of MDR-TB patients.
\end{abstract}

Methodology: A prospective study was carried out in National Tuberculosis Centre Bhaktapur Nepal. Questionnaires were used to collect data from patients.

Results: Total 101 MDR TB patients were included among them majorities were male (52\%) and mean age of the patients was 31.2 years. Majority of patients (87.1\%) had previous history of tuberculosis treatment and $54.5 \%$ were in intensive phase of treatment. The side effect associated with drugs used in treatment of MDR-TB reported by patients were joint pain $(21.2 \%)$, nausea $(20.3 \%)$, hearing disturbances $(11 \%)$, gastrointestinal disturbance $(9.9 \%)$, depression $(9.6 \%)$, itching $(8.1 \%)$, hypothyroidism $(6.4 \%)$, dizziness $(6.4 \%)$, seizures $(3.8 \%)$ and hepatitis $(3.5 \%)$. Last month $25.74 \%$ patients missed one or more doses of drugs and $3.9 \%$ missed drug doses due to side effect of drugs. Majorities of the patients used vehicle to reach health centre $(92.07 \%)$, time to reach the health center $(59.4 \%)$ were less than 30 minutes but majorities of patients $(57.4 \%$ ) were not satisfied by the counseling of health care worker.

Conclusion: The finding of this study shows that in MDR patients $12.8 \%$ were found new cases. Last month $3.9 \%$ patients were stopped the drugs due to side effects of drugs. Majority of patients $(57.4 \%)$ were not satisfied by counseling of health care worker. Treatment of multi drug resistant tuberculosis with second line anti tubercular drugs is associated with side effects, health care worker counseling to MDR- TB patients with full attention is essential to encourage the patient's moral and complete the treatment. Timely managing the side effects of medication is important in helping people to complete their treatment.

Key words: DOTS-plus, Mycobacterium tuberculosis, Second line anti tubercular drugs, Side effects.

\section{INTRODUCTION}

Tuberculosis (TB) is a major public health problem in Nepal. About 45 percent of the total population is infected with TB, of which 60 percent are adult. Every year, 45,000 people develop active TB, of

\author{
Correspondence: \\ Dr. Chandra Prakash Bhatt \\ Associate Professor and Head of Department \\ Department of Microbiology \\ Kathmandu Medical College Public Limited \\ Sinamangal, Kathmandu, Nepal \\ E-mail: drcpbhatt@yahoo.com, drcpbhatt@gmail.com
}

whom 20,580 have infectious pulmonary disease. Treatment by Directly Observed Treatment Short course has significantly reduced the number of deaths; however 5,000 to 7,000 people still die per year from TB. ${ }^{1}$ Directly Observed Treatment of Short Course - Plus is a part of DOTS program that adds approach for multidrug resistance tuberculosis diagnosis, management and treatment. Globally treatment outcomes for multidrug-resistant Mycobacterium tuberculosis remain poor and this is compounded by high drug toxicity.

Second line drugs are frequently associated with very high rates of unacceptable adverse drug reactions, needing frequent interruption and 
change of regimen. Some authors reported that $41 \%$ patients experienced some side effects and only $21.1 \%$ patients required stoppage or change of drug in their study of 39 patients of MDR-TB. ${ }^{2}$ Close monitoring of the patients is necessary to ensure that the adverse effects of second line drugs are recognized quickly. The ability to monitor patients for adverse effects daily is one of the major advantages of Directly Observed Treatment as in category IV treatment running as a pilot project in some states of India. The majority of adverse effects are easy to recognize. Commonly, patients will volunteer that they are experiencing adverse effects. However, it is important to have a systematic method of patient interviewing since some patients may be reticent about reporting even severe adverse effects. Other patients may be distracted by one adverse effect and forget to tell the physician about others. The physician should be trained to screen patients regularly for symptoms of common adverse effects: rashes, gastrointestinal symptoms (nausea, vomiting, and diarrhea), psychiatric symptoms (psychosis, anxiety, depression, and suicidal ideation), jaundice, ototoxicity and peripheral neuropathy. ${ }^{3}$ Prompt evaluation, diagnosis and treatment of adverse effects are extremely important, even if the adverse effect is not particularly dangerous. If the adverse effect is mild and not dangerous like peripheral neuropathy, continuing the treatment regimen, with the help of ancillary drugs if needed, is often the best option. ${ }^{4}$ MDR-TB is a growing hazard to human health worldwide and threat to control of tuberculosis. ${ }^{5}$ Treatment of MDR-TB is difficult, complicated, much costlier, challenging and needs experience and skills. Reserve drugs are frequently associated with very high rates of unacceptable adverse drug reactions, needing frequent interruption and change of regimen. ${ }^{6}$ All measures should be taken to persuade and encourage patients not to stop treatment despite all its discomforts to prevent morbidity, mortality and transmission of MDR-TB. The aims of this study were to find out side effect associated with drugs used in MDR tuberculosis and treatment related factors of TB patients in Kathmandu valley.

\section{METHODOLOGY}

\section{Study Design}

A prospective study was carried out to DOTS-plus program of Kathmandu valley among multi drug resistant tuberculosis patients.

\section{Study Area}

The study was conducted in National Tuberculosis
Center, Thimi, Bhaktapur Nepal from July 2012 to November, 2012.

\section{Study Population}

Patients who have multi-drug resistant tuberculosis and undergoing treatment through DOTS-plus programme in Kathmandu valley were included in this study.

\section{Inclusion and Exclusion Criteria}

Patients who have multi-drug resistant tuberculosis and undergoing treatment through DOTS-plus therapy for at least one and half month in the fiscal year 2011/12 and those who gave informed consent and willing to participate in the study were enrolled.

\section{Ethical Consideration}

Technical and ethical approval was taken from respective authorities to carry out this research work. Verbal informed consent was achieved prior to data collection from each patient who met the study inclusive criteria and briefly explained the aim of the study. Patient was assured to maintain strict confidentiality.

\section{Data Collection}

An interview was conducted to collect the data from the patients and questionnaire was adopted in this study. Patient name, age, TB history were rechecked immediately after interview by monitoring DOTS plus register. The interview was carried out in Nepali language.

\section{Data Analysis}

Data were coded and edited after which they were entered in datasheet created in SPSS Version 16.0. Cross checking was done to find out any mistaken entries in the spreadsheet. Data was presented by chart and diagrams.

\section{RESULTS}

It was found that majorities of the patients were male $(52 \%)$ (Figure 1), intensive phase of treatment (54.5\%) (Figure 2), and previous history of TB treatment (87.1\%) (Figure 3) As reported by patients $25.74 \%$ had missed one or more doses of drugs and $11.5 \%$ missed four doses of drugs during last month (Figure 4). Last month 3.9\% patients missed drug doses due to side effects of the drugs (Figure 5). Common side effect reported by patients were joint pain $(21.2 \%)$, nausea $(20.3 \%)$ hearing disturbances (11\%), and gastrointestinal disturbance $(9.9 \%)$ (Table1). Majorities of the 
respondents used vehicle to reach health centre $(99 \%)$, time to reach the health center $(59.41 \%)$ was less than 30 minutes and waiting time $(64.36 \%)$ was less than 15 minutes but majorities of patients $(57.4 \%)$ were not satisfied by the counseling of health care work (Table 2).

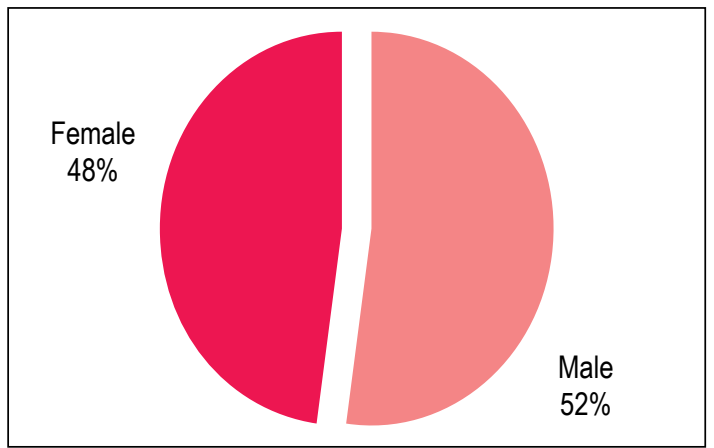

Figure 1. Gender wise distribution of MDR-TB patients

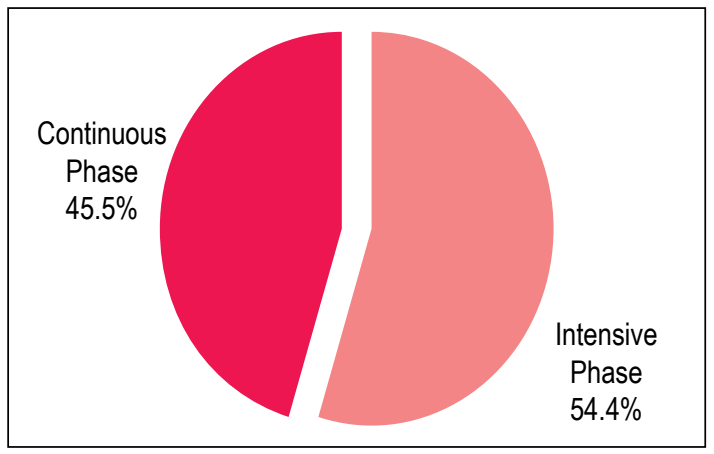

Figure 2. Treatment phase of patients

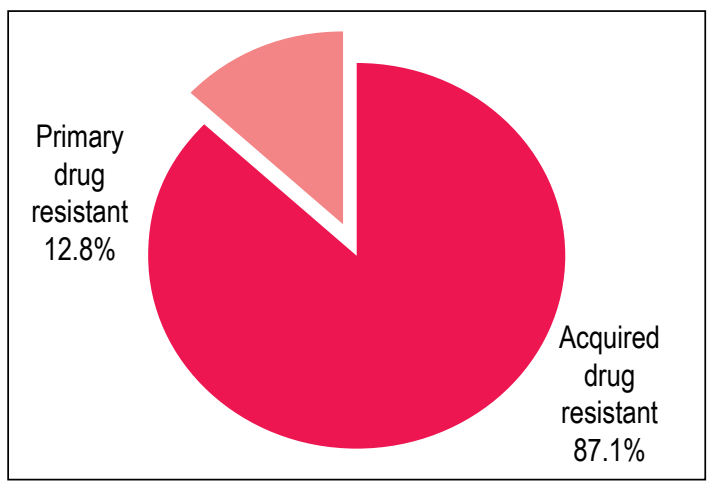

Figure 3. Treatment history of patients

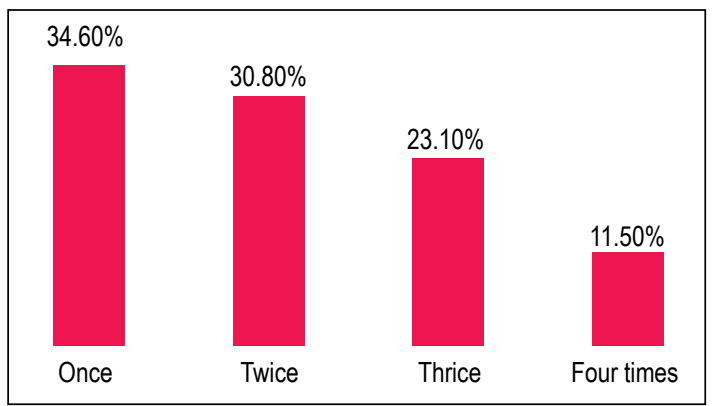

Figure 4. Frequency of missed doses of drugs $(n=26)$

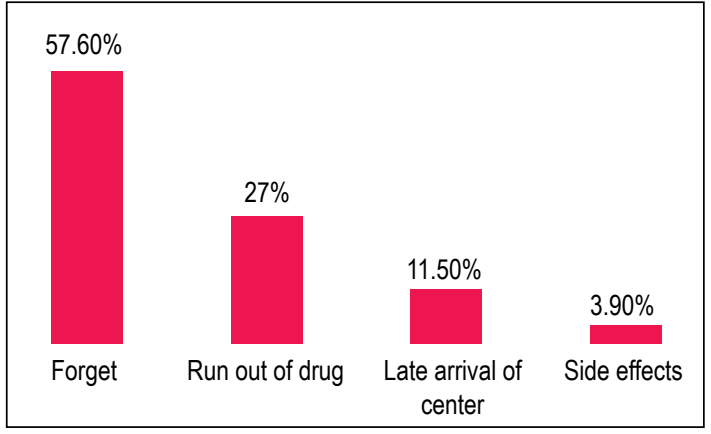

Figure 5. Reason for missed drugs doses ( $\mathrm{n}-26)$

\begin{tabular}{|c|c|}
\hline Side-effects & Percentage (\%) \\
\hline Joint pain & 21.2 \\
\hline Nausea & 20.3 \\
\hline Hearing disturbances & 11.0 \\
\hline Gastrointestinal disturbance & 9.9 \\
\hline Depression & 9.6 \\
\hline Itching & 8.1 \\
\hline Hypothyroidism & 6.4 \\
\hline Dizziness & 6.4 \\
\hline Seizures & 3.8 \\
\hline Hepatitis & 3.5 \\
\hline
\end{tabular}

Table 2. Health system related factors of MDR-TB patient

\begin{tabular}{|l|l|l|}
\hline \multicolumn{1}{|c|}{$\begin{array}{c}\text { Health system related } \\
\text { factors }\end{array}$} & Frequency & Percentage \\
\hline $\begin{array}{l}\text { Convenience } \\
\text { Yes }\end{array}$ & 59 & $58.42 \%$ \\
No & 42 & $41.58 \%$ \\
\hline $\begin{array}{l}\text { Means of vehicle } \\
\text { On foot } \\
\text { By vehicle }\end{array}$ & 8 & $7.9 \%$ \\
\hline $\begin{array}{l}\text { Time to reach } \\
<30 \text { min }\end{array}$ & 93 & $92.08 \%$ \\
$>=30$ min & 60 & $59.41 \%$ \\
\hline $\begin{array}{l}\text { Waiting time } \\
<15 \text { min } \\
>=15 \text { min }\end{array}$ & 41 & $40.6 \%$ \\
\hline $\begin{array}{l}\text { Perception on waiting } \\
\text { time }\end{array}$ & 75 & $64.36 \%$ \\
Reasonable & 36 & $35.64 \%$ \\
Not reasonable & 26 & $74.26 \%$ \\
\hline $\begin{array}{l}\text { Counselling } \\
\text { Yes }\end{array}$ & 43 & 25.74 \\
No & 58 & $57.43 \%$ \\
\hline
\end{tabular}




\section{DISCUSSION}

Multi drug resistant tuberculosis is defined as disease due to Mycobacterium tuberculosis that is resistant to isoniazid $(H)$ and rifampicin $(R)$, with or without resistance to other drugs. Primary drug resistance is defined as drug resistance in a patient who has not received any anti-tubercular treatment in the past, while acquired drug resistance is defined as resistance that develops in a patient who has received prior chemotherapy. ${ }^{7}$ Drug resistant TB is caused by inconsistent or partial treatment, when patients do not take all their drugs regularly for the required period because they start to feel better, and doctors and health workers prescribe the wrong treatment regimens or the drug supply is unreliable.

This study shows that male and female ratio is not statistically significant (1.1:1) and mean age of patient was 31.2 years. Majorities of MDR patient had previous history of TB treatment but $12.8 \%$ were new cases or primary drug resistant. This finding is consistent with the earlier study conducted by Singla et al in India found that mean age of MDR TB patient was 26 years and history of contact with tuberculosis patient $22 \%$ reported yes, $64 \%$ no and $14 \%$ not known. ${ }^{8}$ This finding suggests that TB is common among the economically active group having direct impact to the family and the national economy. This finding also supports the global burden of TB in developing countries where $75 \%$ of cases are within the economically and most productive age group (15-54years). ${ }^{9}$ This finding of the study also suggests that burden of TB will cause economic loss to the family and community in Nepal because it is found that an adult with $\mathrm{TB}$, in the developing world loses on average 3-4 months of work time, $20 \%-30 \%$ of annual house hold income and 15 years income if patient dies causing staggering economic loss to the family and the community. ${ }^{10}$

This study shows that side effects of drugs used in treatment of MDR tuberculosis reported by patients were joint pain $(21.2 \%)$, nausea $(20.3 \%)$, hearing disturbances (11\%), gastrointestinal disturbance $(9.9 \%)$, depression $\quad(9.6 \%)$, itching $(8.1 \%)$, hypothyroidism $(6.4 \%)$, dizziness $(6.4 \%)$, seizures (3.8\%) and hepatitis (3.5\%).This finding is consistent with the earlier finding by Torun et $a{ }^{11}$ reported that one or more side effects developed in 182 cases (69.2\%). These effects led the clinicians to withdraw one or more drugs from the treatment regimen in 146 cases $(55.5 \%)$. Side effects observed most frequently included: ototoxicity (41.8\%), psychiatric disorders $(21.3 \%)$, gastrointestinal disturbance (14.0\%), arthralgia $(11.4 \%)$, epileptic seizures $(9.9 \%)$, hepatitis (4.5\%), and dermatological effects (4.5\%). A study conducted by Singla et a $\beta$ in India shows that fiftyone $(40 \%)$ patients had minor side effects that were manageable. However, $22(18 \%)$ patients had major adverse reactions requiring removal of the offending drug(s) from the regime. Cycloserine produced major psychotic adverse reactions and had to be stopped in 15 patients. Kanamycin was the second most common drug to require interruption in five patients due to hearing loss and giddiness. International experience from five different initial DOTS-plus sites shows that only $2 \%$ of patients stopped treatment, but that $30 \%$ required removal of the offending drug(s) from the regimen due to adverse events. ${ }^{12}$ Managing major adverse reactions requires the help of specialist doctors and poses a challenge in resource poor countries. AntiTB drug side effects are an inherent risk for patients commencing any type of anti-TB therapy, especially the drug-resistant cases. The Peruvian Ministry of Health has notified side-effects prevalence of $3.3 \%$ amongst treated patients. ${ }^{13}$ The emergence of side effects may depend on patients' characteristics but also on concomitant events during therapy. ${ }^{14}$ Drugs associated with MDR-TB treatment is one of the most important factors associated with adverse reactions, increasing risk around 11 times compared to those who received first-line therapy. A prior study involving MDR-TB patients in Peru reported that $95 \%$ of treated patients had a type of adverse reaction to second-line TB drugs, with a proportion of $54 \%$ as toxic reactions. ${ }^{15}$ Others studies have found high prevalence (more than $50 \%$ ) of adverse drug reactions among MDR-TB patients ${ }^{16,11}$ compared to the expected prevalence of mild reactions in those using first-line therapy (around $5-20 \%$ ). ${ }^{17}$ In general, drugs for treating MDR-TB strains have greater toxicity effects and involve a long-term exposure (18 to 24 months), all in great contrast with the treatment of a sensitive strain of TB. ${ }^{17}$ Drug regimens for MDR-TB use agents in combination that are more toxic than the first-line drugs. Further, some anti-tuberculosis drugs used in second-line regimens for drug resistant tuberculosis also potentiate the toxicity of other agents used in the regimen. ${ }^{18}$ Psychiatric adverse effects are known in the treatment of 
tuberculosis and are associated with increased mortality and unfavourable prognosis. ${ }^{19}$

Majorities (92.07\%) of the patients used vehicle to reach health centre, $59.4 \%$ of patients' time to reach the health center was less than 30 minutes and $64.3 \%$ patients waiting time was less than 15 minutes. A study conducted by Moranker et a/20 reported that regular treatment under DOTS is also influenced by the cost, related to the treatment, such as fees of health care providers, travel cost and opportunity costs. For obvious reasons it is a more important barrier for women, who are poor and if they lower status. The most important reason for defaulting was economic conditions of the TB patients-unstable, irregular employment, lack of family support when the TB patient stops earning due to his illness. ${ }^{21} \mathrm{~A}$ study carried out by Lee et $a^{22}$ reported that the financial support of the family become important in the continuation phase and patients who had no financial support had thrice the risk for defaulting. Major factors influencing treatment interruption are access to treatment such as distance, cost of transport, time, waged lost, and quality of drugs, levels of knowledge about TB and flexibility for transfer to another facility.

Finding of this study shows that $25.74 \%$ patients had missed one or more doses of MDR-TB drugs. Patients who did not know the consequence of incomplete treatment might at any stage of treatment stop taking the drugs. This interruption results in emergence of drug resistance to anti-TB drug. Above finding of this study suggests that more emphasis should be given on teaching patients about consequences of incomplete treatment. The premature interruption of treatment represents a problem for patients, their families and those who care for them, and those responsible for TB programmes.

In this study majorities of the respondents (57.4\%) were not satisfied by the counselling of health care worker. Health care workers role is vital to control tuberculosis. TB patients fully depend on their advice. Their minor mistake or careless creates major problems. Health workers should teach TB patients' simple measures how to decrease the risk of transmitting TB, dose and side effects of medicine, and what is the consequence if drug doses are not completed. Health care worker properly counselling them their full attention is essential to encourage the patient moral and complete tuberculosis treatment.

\section{CONCLUSION}

The finding of this study shows that in MDR-TB patients $12.8 \%$ were found new cases or primary drug resistant. Last month $3.9 \%$ patients were stopped the drugs due to side effects of drugs and common side effects of drugs reported by patients were joint pain, nausea, hearing disturbance, gastrointestinal disturbance and depression. Majority of patients $(57.4 \%)$ were not satisfied by counselling of health care worker. Treatment of multi-drug resistant tuberculosis with second line anti tubercular drugs is associated with side effects, health care worker counselling to MDR- TB patients with full attention is essential to encourage the patient's moral and complete the treatment. Timely managing the side effects of medication is important in helping people to complete their treatment.

\section{REFERENCES}

1. National Tuberculosis Control Programme, 2014.

2. Prasad R, Verma SK, Sahai S, Kumar S, Jain A. Efficacy and safety of kanamycin, ethionamide, PAS and cycloserine in multi-drug resistant pulmonary tuberculosis patients. Indian $\mathrm{J}$ Chest Dis Allied Sci 2006;48:183-86.

3. Nathanson E. Adverse events in the treatment of multidrug resistant tuberculosis: results from the DOTS-Plus initiative. Int $\mathrm{J}$ Tuberc Lung Dis 2004;8:1382-84.

4. Shin SS, Hyson AM, Castaneda C, Sanchez E, Alcantara F, Mitnick CD et al. Peripheral neuropathy associated with treatment for multidrug-resistant tuberculosis. Int J Tuberc Lung Dis 2003;7:347-53.

5. Cohn DL, Bustreo F, Raviglione MC. Drug resistant tuberculosis. Review of the world wide situation and the WHO / IUATLD Global Surveillance Project, International Union Against Tuberculosis and Lung Diseases. Clin Infect Dis 1997;24:S121-S130.

6. Furin JJ, Mitnick CD, Shin SS, Bayona J, Becerra MC, Singler JM et al. Occurrence of serious adverse effects in patients receiving communitybased therapy for multidrug-resistant tuberculosis. Int J Tuberc Lung Dis 2001; 5:648-55.

7. Prasad R. Management of multi drug resistant tuberculosis: Practitioner's view point; Guest Lecture. Indian J Tuberc 2007;54:3-11. 
8. Singla R, Sarin R, Khalid UK, mathyria K, Singla N, Jaiswal A, Puri MM et al. Seven-year DOTS-Plus pilot experience in India: results, constraints and issues. Int J tuber Lung Dis 2009(8);976-981.

9. SAARC Tuberculosis and HIVIAIDS centre. Tuberculosis in the SAARC Region, an update. SAARC Tuberculosis and HIVIAIDS Centre, Kathmandu Nepal, 2007.

10. SAARC TB Centre. Gender differences among TB patients in NTPs within SAARC Member Countries. SAARC TB Centre, Kathmandu Nepal. January 2002.

11. Törün T, Güngör $G$, Ozmen I, Bölükbaşi $Y$, Maden E, Biçakçi B, Ataç G, Sevim T, Tahaoğlu K. Side effects associated with the treatment of multidrugresistant tuberculosis. Int J Tuberc Lung Dis. 2005 Dec; 9(12):1373-7.

12. Nathanson E, Gupta R, Huamani P et al. Adverse events in the treatment of multidrug resistant tuberculosis results from the DOTS-Plus initiative. Int J tuber Lung Dis 2004;8:1382-84.

13. Ministerio de Salud. Informe de Gestión: Situación de la Tuberculosis en el Perú. Estrategia Sanitaria Nacional de Prevención y Control de la Tuberculosis. Ministerio de Salud. Lima, Perú 2008.

14. Xia YY, Zhan SY. Systematic review of antituberculosis drug induced adverse reactions in China. Zhonghua Jie He He Hu Xi Za Zhi. 2007;30:419-423.

15. Herrera S, Sanchez E, Lagunam A, Farroñay V. Tuberculosis multidrugoresistente en pacientes adultos mayores tratados en el Hospital Sergio E. Bernales Lima - Perú. Enferm Tórax. 2005;49:181185.
16. Joseph P, Desai VB, Mohan NS, Fredrick JS, Ramachandran $\mathrm{R}$, et al. Outcome of standardized treatment for patients with MDR-TB from Tamil Nadu, India. Indian J Med Res. 2011;133:529-534.

17. Arbex MA, Varella Mde C, de Siqueira HR, de Mello FA. Anti tuberculosis drugs: drug interactions, adverse effects, and use in special situations. Part 1: first-line drugs. J Bras Pneumol.2010;36:626-640.

18. Carroll MW, Lee M, Cai Y, Hallahan CW, Shaw PA, Min $\mathrm{JH}$. Frequency of adverse reactions to firstand second-line anti-tuberculosis chemotherapy in a Korean cohort. Int. J. Tuberc. Lung Dis., 16 (2012); pp. 961-966.

19. Baghaei P, Tabarsi P, Dorriz D, Marjani M, Shamaei M, Pooramiri MV. Adverse effects of multidrugresistant tuberculosis treatment with a standardized regimen: a report from Iran. Am. J. Ther., 18 (2011); pp. 29-34.

20. Moranker S, Suryawanshi N. Indian Socio-cultural aspects of tuberculosis among women in Western rural Maharashtha, India. Pune: Foundation of Research in Community Health;2000.

21. Srinivasan S. The economics of TB (online) 2001. Available from: http://www.infochangeindia.

22. Liefooghe R, MuynckAD. Dynamics of tuberculosis adherence. Islamabad: VLIR Project, Saialkot; 2001. 